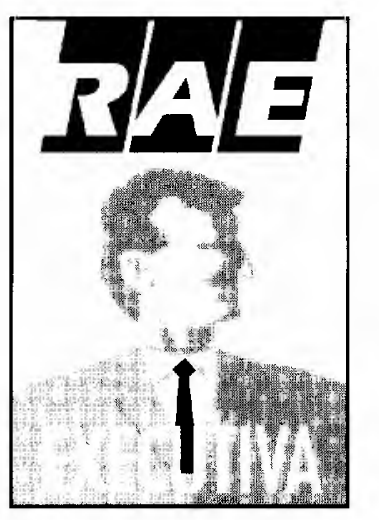

\title{
REENGENHARIA: UM GUIA DE REFERÊNCIA PARA O EXECUTIVO
}

* José Ernesto Lima Gonçalves

A posição da reengenharia entre as abordagens existentes para melhoria organizacional e dos negócios.

The reengineering position among the available approaches to organizational and business improvement.

\section{PALAVRAS-CHAVE:}

Reengenharia, planejamento empresarial, processos organizacionais, organização do trabalho, consultoria organizacional, mudança organizacional.

\section{KEY WORDS:}

Reengineering, business planning, business processes, business organization, orga. nizational consulting, organizational change.
As profundas mudanças que estão ocorrendo em todas as dimensōes do mundo contemporâneo exigem que as empresas estejam adaptadas para que possam sobreviver. Para dar base à discussão das estratégias disponíveis para essa adaptação, preparamos este resumo sobre a reengenharia, um dos mais co- mentados e pouco entendidos temas gerenciais da atualidade. É de importância fundamental que os executivos conheçam esse assunto, para que possam se posicionar a seu respeito com relação à empresa.

A bibliografia básica sobre o assunto ainda é o livro de Michael Hammer e

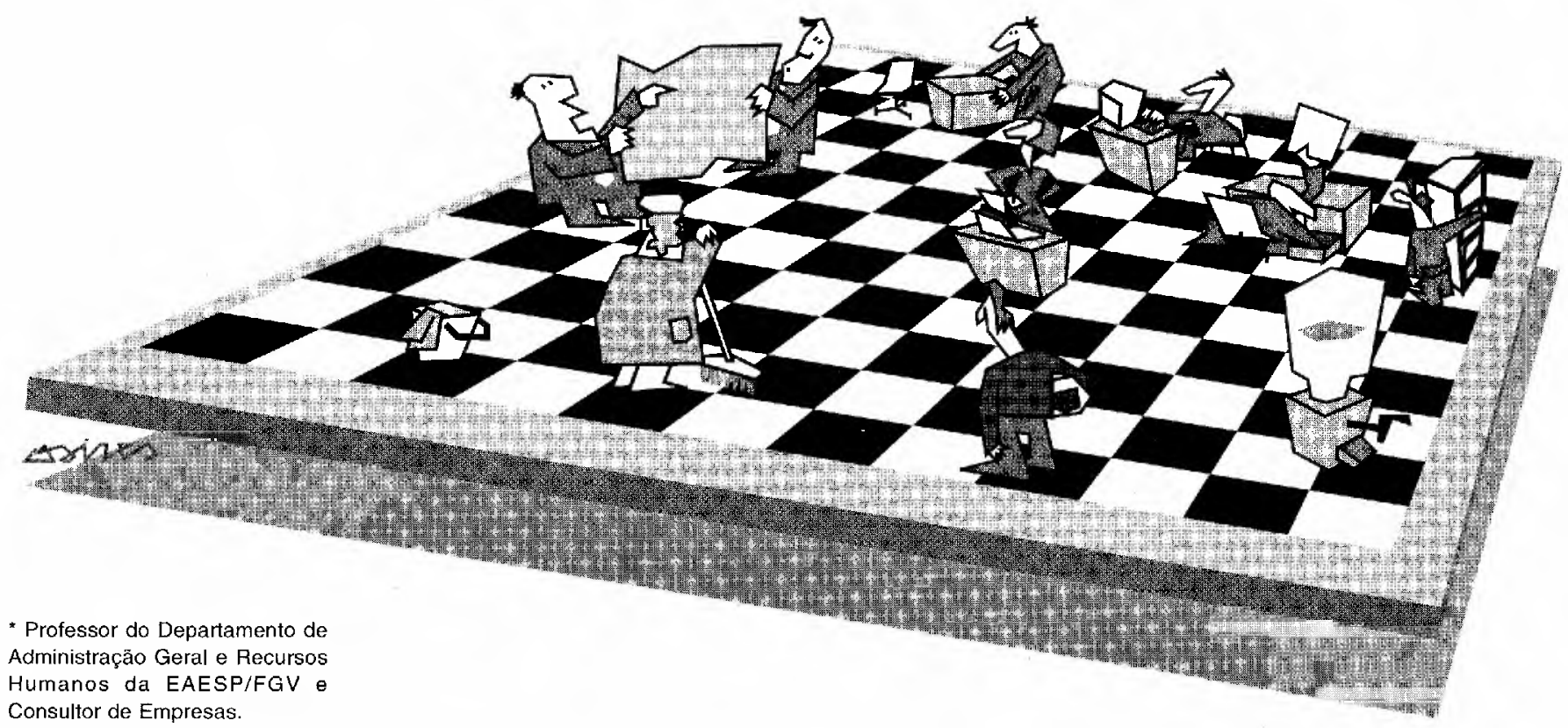

Consultor de Empresas. 
1. HAMMER, Michael, CHAMPY, James. Reengenharia. Rio de Janeiro: Campus, 1993.

2. Idem, ibidem.

3. JOHANSSON, Henry et al Business process reengineering. Wiley, 1993.

4. HAMMER, Michael, CHAMPY, James. Op. cit.

5. HAMMER, Michael, Reengineering work: don't automate, obliterate. Harvard Business Review, Boston, Jul./Ago. 1990.
James Champy, Reengenharia. ${ }^{1}$ De leitura aparentemente simples, o livro, na verdade, é um manifesto e seus autores procuram claramente marcar uma posiçăo diferenciada no campo dos conceitos de estratégia de gestão. Eles mostram que as empresas em geral não estão preparadas para o futuro e oferecem a reengenharia como um caminho possível para a reformulação necessária. Mais do que isso, eles demonstram que as bases conceituais das nossas empresas estão equivocadas $\mathrm{e}$ precisam ser revistas se for para se obter resultados convincentes. É uma leitura que chega a provocar medo em alguns e descrédito em outros pela radicalidade das mudanças que sugere e por não mostrar como realizá-las. Certamente muitas outras fontes deverão ser exploradas, antes que uma equipe possa pretender realizar um processo de reengenharia para valer.

Da maneira como tem sido formalmente apresentada, a reengenharia é a reconcepção fundamental e o reprojeto radical dos processos empresariais para se obter ganhos dramáticos nos indicadores de desempenho da empresa: custo, qualidade, serviço e resultados. ${ }^{2} \mathrm{O}$ próprio sintetizador da idéia salienta que a reengenharia não tem nada a ver com aperfeiçoar as atividades ou consertar os defeitos das empresas. Outros autores apresentam suas próprias definições apenas superficialmente diferentes desta, mas existem algumas pessoas que insistem numa grande confusão conceitual.

A reengenharia se baseia na idéia fundamental de processo, que é uma coleção de atividades seqüenciais que toma um ou mais tipo de insumos e cria um produto que tem valor para seus clientes. ${ }^{3} \mathrm{~A}$ idéia de processo é familiar para quem trabalha com manufatura, mas não é tão natural para as pessoas das demais áreas da empresa. A visão de processos não se limita ao processo de fabricação industrial e a reengenharia não se restringe à manufatura. Ao contrário, ela procura identificar os processos que são típicos na realização do trabalho em todas as áreas da empresa. Introduz o interesse pela importância do
A busca incessante de maneiras de aperfeiçoar a gestão das empresas e de melhorar seu desempenho tem levado ao desenvolvimento de inúmeras abordagens que estão em uso nas empresas. Se perguntarmos o que há de novo sobre modernização da gestão das empresas, vamos ouvir que reengenharia é apenas um outro nome para assuntos tão diferentes como orçamento base-zero, O\&M radical, TQM, programa de produtividade administrativa, processos de racionalização administrativa, revisão de normas e procedimentos, cortes de custos e o que mais as pessoas lembrarem. Existem até mesmo alguns artigos e livros que procuram esclarecer que esses conceitos são todos muito semelhantes, o que é claramente inaceitável. ${ }^{4} \mathrm{Na}$ verdade, a reengenharia não é nenhuma dessas coisas e o único ponto de contato é a grande noção de aperfeiçoamento do desempenho da empresa, já que mesmo em termos de objetivos específicos, ela se diferencia dessas outras técnicas administrativas.

A reengenharia é novidade na radicalidade da sua proposta, na busca do essencial, na orientação para a definição do negócio e na abordagem top-down. É única na integração desses pontos inovadores na busca do melhor desempenho da empresa.

A reengenharia começou com a preocupação de quebrar as regras antigas que definiam como funciona vam os processos nas empresas. ${ }^{5}$ Todas as empresas operam com base em muitas regras não escritas, muitas das quais envolvem premissas não obrigatoriamente válidas. Apressar esses processos através da automação não melhora as suas fallhas estruturais. $O$ próprio 
Hammer diz que as idéias da reengenharia são óbvias, mas que ninguém as adotava para valer. ${ }^{6}$

A reengenharia, como abordagem básica para a reformulação de empresas, integra idéias inovadoras de alto potencial: grupos de alto desempenho, abordagem por processos empresariais, custeio baseado nas atividades $(A B C)$, integração de tarefas por meio de tecnologia etc. Ela cria o ambiente propício para o aproveitamento da experiência adquirida, sem as amarras dos procedimentos anteriores.

Ela tem pontos de contato com muitas outras abordagens, especialmente os programas integrados de qualidade. ${ }^{7}$ Pode ser realizada ao mesmo tempo em que esforços de TQC ekaizen são implantados em áreas diferentes da empresa. Além disso, o processo que passou por uma reengenharia pode e deve ser calibrado e ajustado permanentemente por meio de técnicas de aperfeiçoamento contínuo.

A reengenharia tem uma profunda integração, que chega a ser interdependência, com a tecnologia de informação - TI. É a TI que viabiliza, rião apenas a análise e a simulação de novas maneiras de realizar as operações empresariais, mas, principalmente, a execução dessas novas maneiras de realizar o trabalho nas empresas.

A reengenharia é uma abordagem típicamente top-down. ${ }^{8}$ Aliás, a sua proposta de rediscutir a organização a partir da definição do negócio e da justificativa dos investimentos dificilmente poderia começar em qualquer outro lugar da organização que não fosse o nível decisório mais alto. A relação da reengenharia com a estratégia da empresa é clara, embora muitas vezes esquecida na prática. A reengenharia cuida das operações e apenas a estratégia pode dizer quais operações são importantes. ${ }^{9}$ Por outro lado, não faz sentido investir esforço intelectual, físico e financeiro em operações que não interessam mais à empresa.

\section{OS VÁRIOS NOMES DA REENGENHARIA}

Existem diversos nomes semelhantes para a reengenharia no mercado. Cada um deles foi criado por uma empresa de consultoria, com uma definição ligeiramente diferente das demais, de modo a refletir a estratégia, o escopo e a ênfase de cada
Quadro 1

\begin{tabular}{|c|c|c|c|c|}
\hline & Nome Original & $\begin{array}{l}\text { Nome em } \\
\text { Portugués }\end{array}$ & Empresa & Aulor. \\
\hline $\mathrm{BPI}$ & $\begin{array}{l}\text { Business, Process } \\
\text { Improverment }\end{array}$ & $\begin{array}{l}\text { Aperfeiloarmento } \\
\text { de Processos }\end{array}$ & $A S Q^{2} G^{\prime}$ & Harrington \\
\hline PI & $\begin{array}{l}\text { Processs } \\
\text { Innovation }\end{array}$ & $\begin{array}{l}\text { Rèingenharia de } \\
\text { processos }\end{array}$ & Emst \& Young & Davenport \\
\hline GP & $4+4 \times 10$ & $\begin{array}{l}\text { Gerenciamento de } \\
\text { processos }\end{array}$ & $\begin{array}{l}\text { Rummler \& } \\
\text { Brache }\end{array}$ & $\begin{array}{l}\text { Rummler } \\
\text { \& Brache }\end{array}$ \\
\hline BPE & $\begin{array}{l}\text { Business Process } \\
\text { Engineering }\end{array}$ & $\begin{array}{l}\text { Engénharia de } \\
\text { Négócios }\end{array}$ & $\begin{array}{l}\text { Texas } \\
\text { Instruments }\end{array}$ & \\
\hline GPR & $\begin{array}{l}\text { Core Process } \\
\text { Beerigineering }\end{array}$ & $\begin{array}{l}\text { Reengénharia de } \\
\text { Prócessos }\end{array}$ & McKinsey & $x^{4}+x^{4}$ \\
\hline BPR & $\begin{array}{l}\text { Business Process } \\
\text { Reehgineering }\end{array}$ & $\begin{array}{l}\text { Reengenharia de } \\
\text { Processos }\end{array}$ & $\begin{array}{l}\text { Coopers } 8 \\
\text { Lybrand (UIO) }\end{array}$ & Johansson \\
\hline BPRI & $\begin{array}{l}\text { Businessprocess } \\
\text { Redesign }\end{array}$ & $\begin{array}{l}\text { Redesenho dos } \\
\text { Processos de } \\
\text { Negógio }\end{array}$ & $\begin{array}{l}\text { Coopers \& } \\
\text { Lybrand. } \\
\text { (USA) }\end{array}$ & Knorr in al \\
\hline$B \hat{R}^{2}$ & $\begin{array}{l}\text { Business } \\
\text { Reengineering }\end{array}$ & $\begin{array}{l}\text { Reengenharia de } \\
\text { Empresa }\end{array}$ & findax & Hammer \\
\hline
\end{tabular}

abordagem (ver quadro1).

O escopo do processo de reengenharia pode ser definido em termos de duas dimensões: a abrangência e a profundidade. ${ }^{10}$ A abrangência é definida em termos de amplitude horizontal com relạção à estrutura da empresa. Pode ir de uma única função organizacional até abranger toda uma unidade de negócios. A profundidade se refere ao grau de intensidade das alterações nos seis principais elementos organizacionais: papéis e responsabilidades; mensuração de resultados e incentivos; estrutura organizacional; tecnologia de informação; valores compartilhados e habilidades.

Essa mesma definição de escopo pode ajudar a compreender a distinção entre as diversas abordagens existentes para o aperfeiçoamento do desempenho da organização. Como nos mostra o quadro 2, a abrangência e a profundidade da intervenção claramente diferentes para cada abordagem permitem a organização dessas abordagens em quatro grandes grupos (ver quadro 2).

Outra distinção que deve ser feita é
6. The Economist. Take a clean sheet of paper..., 01/05/93. ed radical innovation and continuous improvement? Integrate process reengineering and TQM, Planning Review, May/Jun. 1993.

8. HAMMER, Michael, CHAMPY, James. Op. cit

9. STEWART, Thomas. Reenging tool. Fortune, Aug. 1993.

10. HALL, Gene et al. How to make reengineering really work. Harvard Business Review, Boston, Nov./Dec. 1993.
7. DAVENPORT, Thomas. Negineering: the hot new mana- 


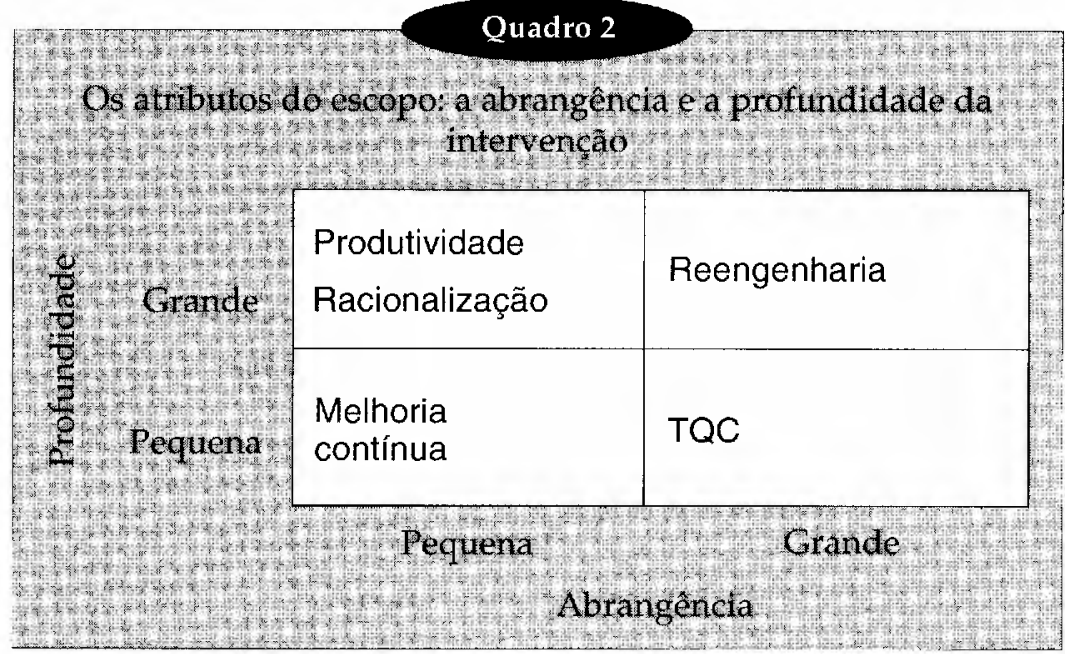

aquela entre reengenharia de negócios e reengenharia de processos. Embora ambas se proponham a trazer ganhos dramáticos e reformulações radicais, a reengenharia de negócios começa pela discussão da própria definição do negócio da empresa. A reengenharia de processos, por sua vez, subordina sua análise à estratégia vigente da empresa e, de certa maneira, começa sua intervenção a partir desse ponto.

As expressões "reengenharia", "melhoria contínua", "redesenho de processo", "desenvolvimento do processo", "aperfeiçoamento do processo de negócios" e outras mais se referem a técnicas e famílias de técnicas diferentes em quase tudo e que se aplicam a situações tão diferentes quanto os medicamentos se aplicam ao tratamento das doenças. A utilização da técnica errada pode não trazer o resultado esperado ou, o que seria pior, pode matar o doente.

Para entender a situação, podemos montar o espectro ${ }^{11}$ das famílias de técnicas de intervenção no desempenho da empresa, que as classifica de acordo com o grau de
11. DAVENPORT Thomas. Reengenharia de processos. Rio de Janeiro: Campus, 1994

12. HAMMER, Michael, CHAMPY, James. Op. cit. radicalidade dessa intervenção. Como podemos observar no quadro 3 , de um lado temos as técnicas características dos programas de qualidade, especialmente aquelas centradas no aperfeiçoamento contínuo do trabalho existente. No outro extremo desse espectro, temos a reengenharia, principalmente a reengenharia de negócio, a forma mais radical de intervenção. No meio, de acordo com a abrangência, a profundidade e o grau de radicalidade do processo, podemos encaixar as demais técnicas: o kaizen, o aperfeiçoamento de processos de trabalho, o aperfeiçoamento dos processos de negócio e o redesenho dos processos, por exemplo. É importante, então, saber escolher a melhor estratégia para promover na empresa a intervenção necessária (ver quadro 3 ).

Este espectro reflete, também, o nível de risco associado ao emprego de cada família de técnicas de aperfeiçoamento da empresa. Evidentemente, os riscos imediatos associados ao emprego de técnicas de aperfeiçoamento contínuo são muito menores do que os decorrentes do abandono de tudo, como preconiza a reengenharia de negócio. A longo prazo, os riscos são totalmente diferentes, até o ponto de haver uma inversão, se, por exemplo, a empresa insistir em promover microajustes em processos desvinculados de seu negócio. Alguns autores comparam o esforço dedicado ao aperfeiçoamento de atividades sem a discussão do contexto maior à tentativa de arrumar as cadeiras do convés do Titanic. ${ }^{12}$

O mesmo espectro de organização das famílias de técnicas facilita a visualização

\section{Quadro 3}

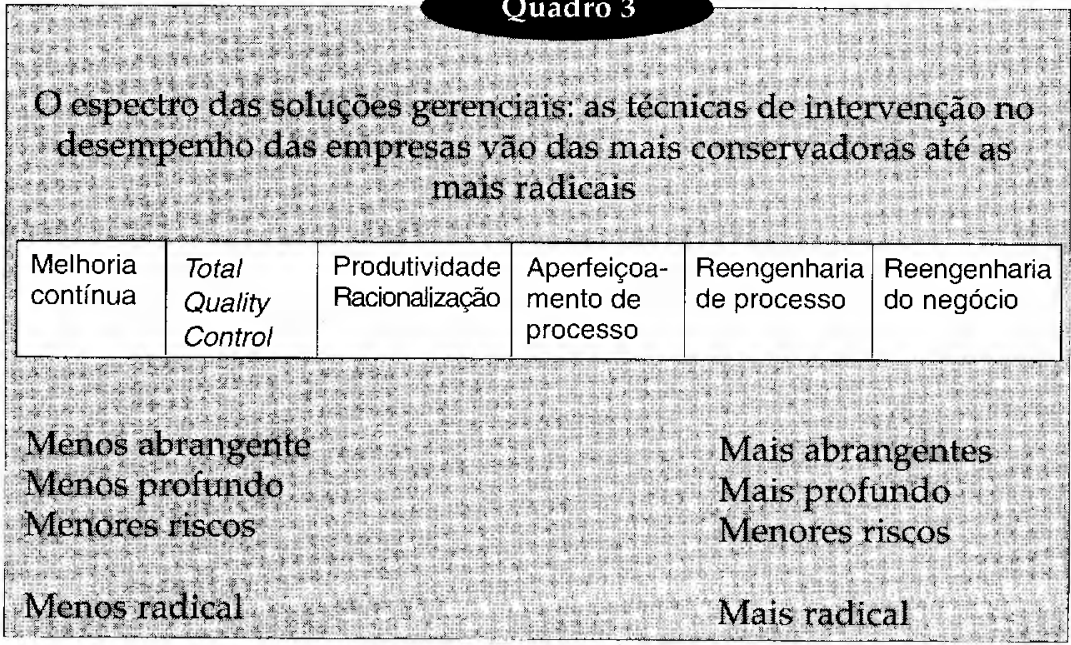




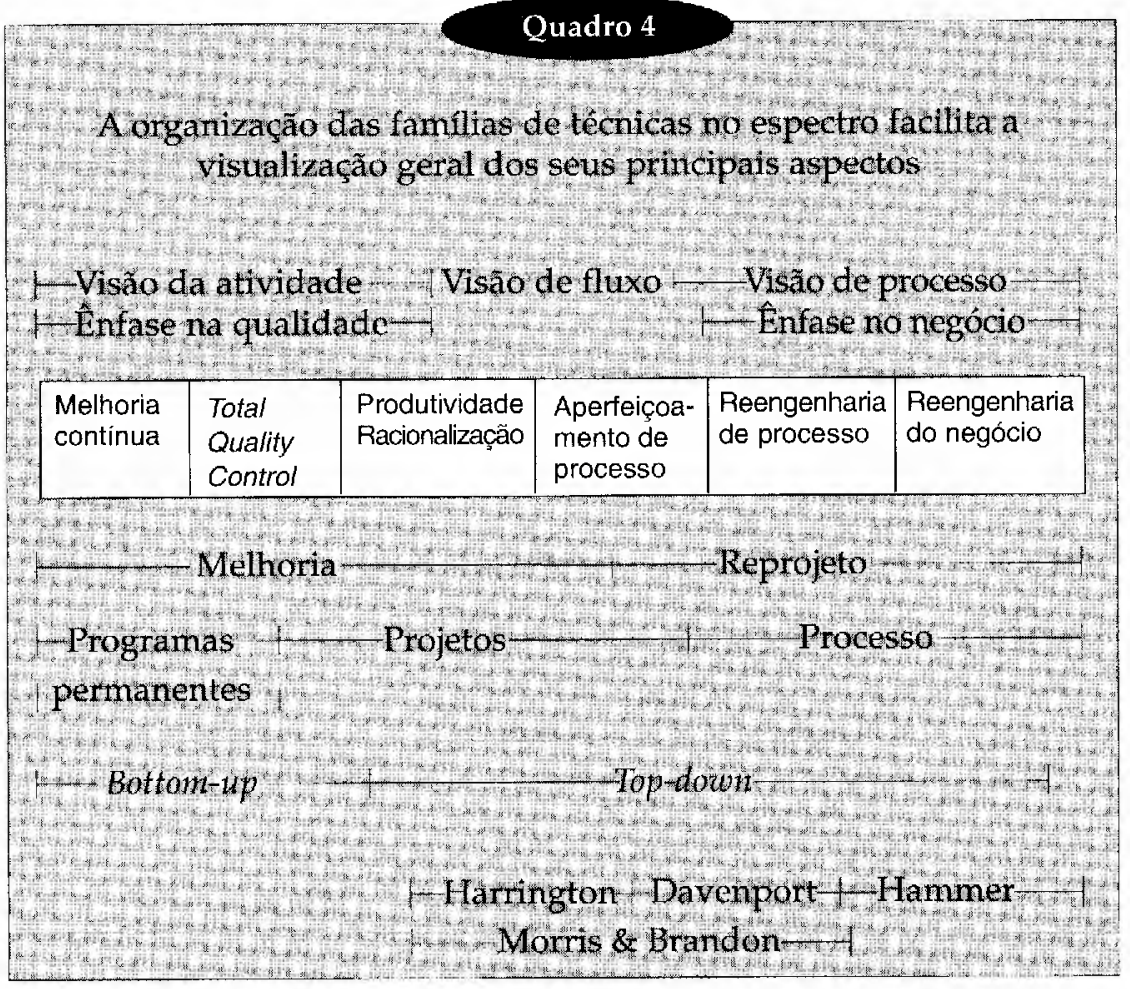

geral dos seus principais aspectos. Enquanto as técnicas típicas de qualidade abordam a empresa com uma visão de atividades, a reengenharia adota a visão dos processos empresariais. A ênfase na qualidade, característica das técnicas do tipokaizen e TQC, é substituída pela ênfase no negócio quando se fala de reengenharia. Talvez a distinçâo mais evidente seja com relação ao ponto de partida de cada uma: as abordagens menos radicais se propõem a realizar a melhoria dos procedimentos existentes, enquanto a reengenharia vai partir do zero no projeto de novas maneiras de operar.

A maioria dos projetos de racionalização e aperfeiçoamento contínuo, inclusive os programas de qualidade, não consegue enxergar o negócio da empresa, nem se centra nele. Contribuem para isto as características típicas desses projetos: a participação maciça dos níveis operacionais, as açōes de curto alcance e os objetivos incrementais. $\mathrm{Na}$ verdade, eles as- sumem que o negócio da empresa está fora de discussāo. Se a atividade é ou não ligada ao negócio não importa, desde que seja bem feita, de acordo com as especificações e com os procedimentos previstos nos manuais.

O quadro 4 também mostra a posição relativa dos autores mais importantes da reengenharia com relação à abordagem que propōem (ver quadro 4): Harrington (mais próximo das técnicas típicas de qualidade), Davenport (precursor da "nova engenharia" de processos), Hammer (o autor da proposta mais radical), Morris e Brandon (que propõem uma abordagem conciliadora). ${ }^{13}$

A comparação entre os extremos do espectro mostrada no quadro 5 pode facilitar o entendimento das diferenças básicas de abordagem e orientar a escolha da
13. HARRINGTON, H. James Business process improvement. McGraw Hill, 1991; DAVENPORT, Thomas. Op. cit.; HAMMER, Michael, CHAMPY, James. Op. cit.; MORRIS, Daniel, BRANDON Joel. Reengenharia: reestruturando a sua empresa. São Paulo: Makron Books, 1994. 
melhor alternativa. As abordagens intermediárias apresentam características que se situam entre esses dois extremos (ver quadro 5).

A seleção da diretriz que norteará o esforço de aperfeiçoamento da empresa e, portanto, a seleção da família específica de técnicas a ser empregada, dependerá dos objetivos estratégicos da empresa.

O mesmo se aplica, por exemplo, aos diversos pontos de entrada no processo de reengenharia. Pode-se começar discutindo o próprio negócio ou a tecnologia do processo produtivo ou mesmo a forma básica de estruturar os recursos produtivos. Mais do que a definição de um ponto de partida, essa escolha tem a ver com a abrangência, a profundidade e o grau de radicalidade do processo de reengenharia a ser adotado e a urgência para a obtenção de resultados (ver quadro 6).

As empresas não são homogêneas, nem na sua estrutura nem nos seus problemas, portanto as técnicas de aperfeiçoamento utilizadas para melhorar o seu desempenho não serão as mesmas na empresa toda. É comum ver a mesma empresa adotar técnicas radicais em determinados processos e apenas ajustes em outros.

Evidentemente, uma empresa satisfeita

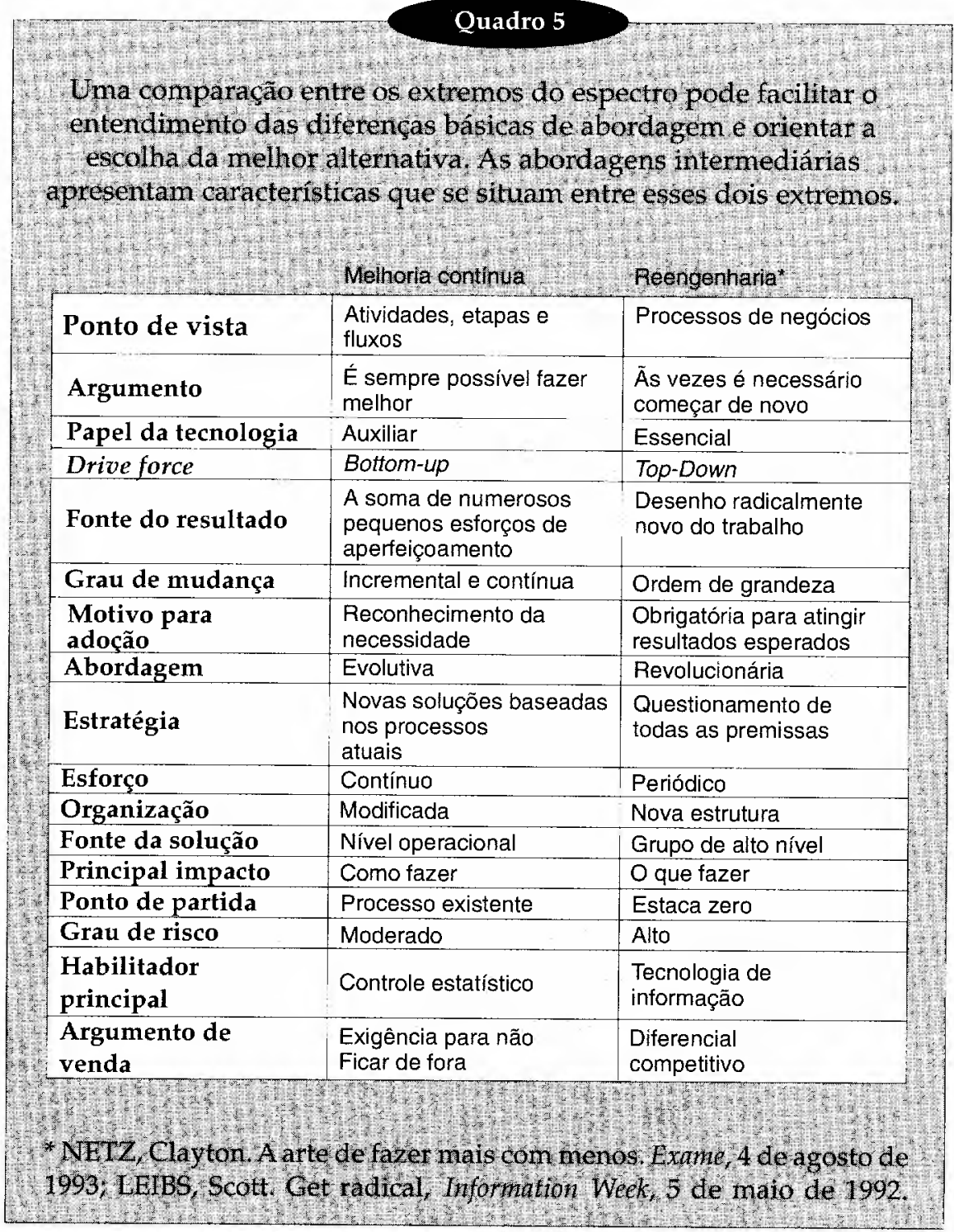


Quadro 6

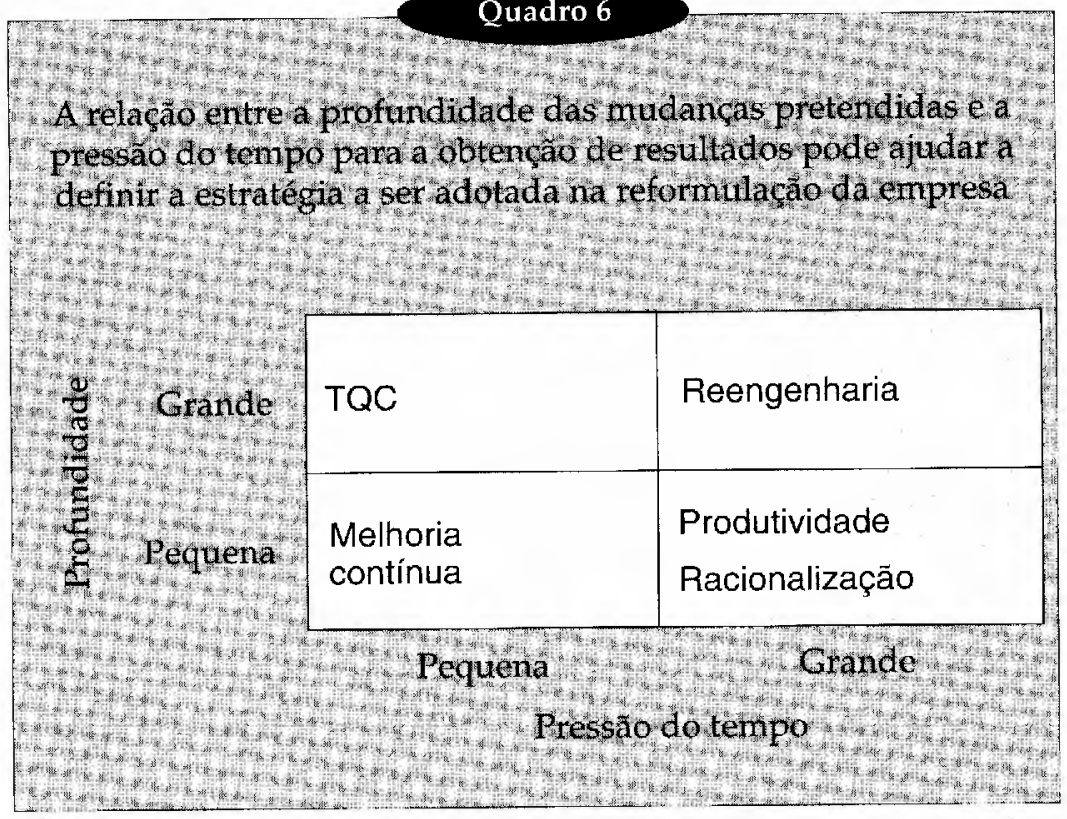

com sua opção de negócio, produto e processo pode se concentrar em melhorar o rendimento dos seus recursos, a aderência aos padrões e a estabilidade do processo. As principais variáveis na seleção da diretriz do processo de aperfeiçoamento da empresa acabarão sendo o ânimo, o ambiente interno, o grau de expectativa e o nível de insatisfação com a situação atual da empresa. É fácil entender que altos níveis de insatisfação e de expectativa aliados a ambiente interno adequado são mais do que condições necessárias para a escolha de processos radicais como a reengenharia: elas praticamente orientam a escolha nessa direção.

Como é possível para a reengenharia fazer o mesmo trabalho com resultados tão diferentes? $\mathrm{O}$ fato é que depois que passou pela reengenharia, o trabalho já não é o mesmo. Embora leve ao mesmo produto final desejado, o faz através de meios tāo diferentes que os custos de obtenção são totalmente diferentes. A reengenharia consegue seus resultados exata14. HAMMER, Michael, CHAMPY, James. Op. cit. mente com a mu- dança profunda da maneira de obter os produtos e serviços da empresa.

As dez mudanças mais freqüentes que ocorrem nas empresas com a reengenharia dos processos são as seguintes: ${ }^{14}$

as unidades de trabalho mudam, passando de departamentos funcionais para equipes de processo;

os serviços das pessoas mudam, passando de tarefas simples para trabalhos multidimensionais:

os papéis das pessoas, antes definidos e controlados pelos gerentes, passam a ser desenhados pelos seus próprios ocupantes;

a preparação dos empregados para o serviço muda, deixando de ser treinamento para ser educação;

o enfoque das medidas de desempenho e da remuneração se altera, da atividade para o resultado;

os critérios de promoção mudam do desempenho individual para a habilidade;

os valores, antes protetores da organização, passam a inspirar a produção;

os gerentes mudam de supervisores para instrutores de seus times;

as estruturas organizacionais mudam de hierárquicas para achatadas;

os executivos deixam de ser controladores do resultado para serem líderes.

Pode-se imaginar que a introdução dessas alteraçōes na empresa leva a mudanças substanciais tanto no seu funcionamento, como nos seus resultados. Os projetos de reengenharia apresentam pontos comuns, que foram sintetizados no quadro 7 . Os impactos que podem ser associados às alteraçôes correspondem ao abandono de inúmeras regras básicas da administração
A ênfase na qualidade, característica das técnicas do tipo kaizen e TQC, é substituída pela ênfase no negócio quando se fala de reengenharia - a reengenharia vai partir do zero no projeto de novas maneiras de operar. 
15. HARRISON, D. Brian et al. A methodology for reengineering businesses. Planning Review. Mar./Apr. 1993.

16. Adaptado de HARRISON, D. Brian et al. Op. cit.

17. FUREY, Timothy. A six step guide to process reengineering. Planning Review, Mar./Apr. 1993; MORRIS, Daniel, BRANDON, Joel. Op. cit.

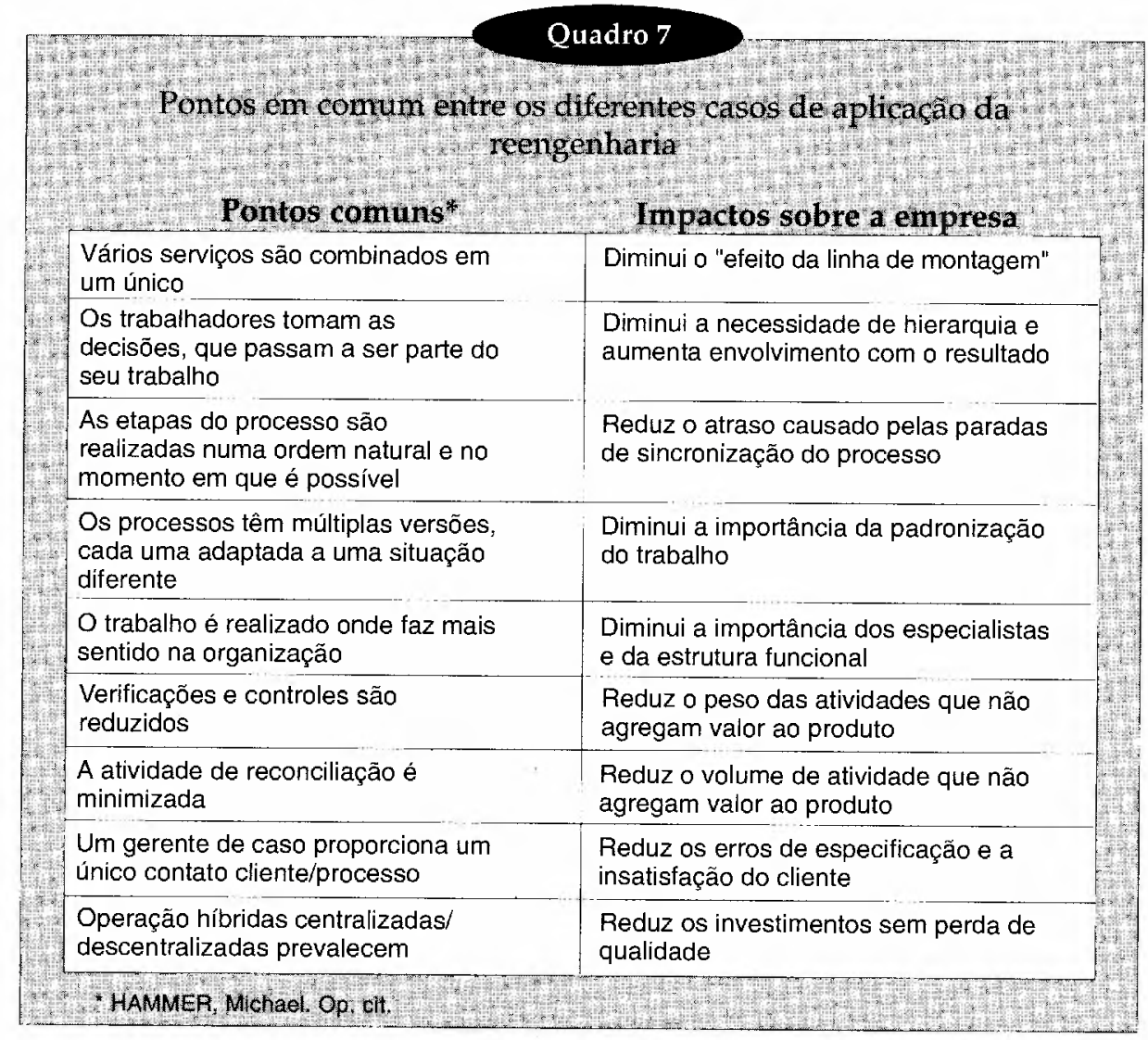

de empresas, que estiveram em vigor por muitas décadas (ver quadro 7).

A reengenharia utiliza basicamente a tecnologia de informação, as novas estruturas organizacionais e as equipes multifuncionais ${ }^{15}$ para obter resultados drásticos nas empresas.

As principais etapas de um projeto de reengenharia podem ser as seguintes: ${ }^{16}$

desenvolvimento da visão de processos: as pessoas precisam ser treinadas a enxergar os processos empresariais na empresa;

definição dos objetivos do projeto: começa com a análise dos objetivos da organização e o estabelecimento da direção básica que o projeto deve seguir; detalhamento de uma proposta de solução: é a fase em que uma nova maneira de fazer as coisas é criada e conta com o apoio de benchmarking, criatividade etc.;

visualizar a solução: corresponde ao estabelecimento de pontes necessárias para chegar aonde queremos a partir do que temos; projetar a solução: inclui o projeto dos novos processos e da nova estrutura organizacional, a definição dos mecanismos de mudança e a preparação do plano de implementação;

implementação dos novos processos: abrange também a criação das condições, seja através dos sistemas de informação, seja através da preparação das pessoas.

Algumas abordagens dedicam muito esforço ao mapeamento dos processos empresariais existentes, o que as leva a cair na análise desses mapas e, portanto, a criar laços indesejáveis com as idéias antigas. ${ }^{17}$

Podemos concluir que todos esses esforços, que buscam o aperfeiçoamento da empresa, levam na mesma direção? Certamente não. Existem muitas técnicas que podem ser utilizadas para melhorar inúmeros aspectos do funcionamento das empresas. Como regra geral, devemos reservar a reengenharia para os processos empresariais que realmente interessam. 